\title{
VERGIFNIS IN DIE GEBED VAN DANIËL
} (DAN. 9:4-19)

\author{
D.F. O’Kennedy ${ }^{1}$
}

\author{
ABSTRACT \\ FORGIVENESS IN THE PRAYER OF DANIEL \\ (DAN 9:4-19)
}

\begin{abstract}
Daniel 9:4-19 is one of the important penitential prayers in the Old Testament. This prayer has been investigated from different perspectives, but the theological dimension of forgiveness is often neglected. In this article the understanding of divine forgiveness is studied and the following important elements are emphasised: (1) Forgiveness cannot be limited to one specific historical context; (2) The motivation for forgiveness does not lie in the people's obedience, but in God's grace and mercy; (3) The structure and content of the prayer implies that confession of guilt is an important element in the process of forgiveness. Everyone is guilty — the guilt is not placed on a certain person or king (cf. v. 7); (4) Forgiveness is meant for the "international" Israel and not limited to a specific geographical area.
\end{abstract}

\section{INLEIDING}

Die gebed van Daniël is reeds vanuit verskillende perspektiewe nagevors: die interpretasie van na-eksiliese boetegebede (Hornig 1957:644-646; Werline 1998); die outentiekheid van hierdie gebed (Jones 1968:488-493); Daniël 9 as liturgiese gebed (La Cocque 1976:119-142); Daniël 9 as refleksie op Jeremia 29 (Wilson 1990:91-99); intertekstualiteit in Daniël 9 (Venter 1997:327-346) en die Deuteronomistiese invloed op Daniël 9:4-19 (Van Deventer 2000:62-75).

Daniël 9:4-19 kan as een van die belangrikste gebede om vergifnis in die Ou Testament getipeer word (vgl. O’Kennedy \& Olivier 1996:503506). Die wortel סלח kom onder andere twee keer in die gebed voor: een keer as selfstandige naamwoord (v. 9) en een keer as werkwoord (v. 19) (Hausmann 1986:862). Hierdie vergifnis-dimensie word dikwels afgeskeep en die skrywer kon geen artikel vind wat spesifiek op vergifnis fokus nie. Ná 'n bespreking van die literêre en historiese dimensie sal die teologiese dimensie van vergifnis nagevors word.

1 Dr. D.F. O'Kennedy, Departement Ou en Nuwe Testament, Fakulteit Teologie, Universiteit van Stellenbosch, Stellenbosch 7602, e-pos: danieok@nghelder.co.za 


\section{LITERÊRE EN HISTORIESE DIMENSIE}

\subsection{Literêre konteks en afbakening}

In die boek Daniël word Daniël as getroue bidder voorgestel wat drie maal per dag tot God gebid het (Dan. 6:11, 12,14). Daar is egter net twee opgetekende gebede in die boek Daniël. Daniël 2:20-23 is 'n kort lofgebed teenoor die lang boetegebed in Daniël 9:4-19 (Conradie 1978:101-105; Louw 1979:105).

Die kwessie van die plasing van die gebed en die eenheid van Daniël 9 is problematies. Daar is ' $n$ hele aantal geleerdes (Charles, Marti, Hartman \& Di Lella, e. a.) $)^{2}$ wat Daniël 9:4-19 as 'n sekondêre gedeelte beskou. Aan die ander kant is daar weer geleerdes (Jones, Porteous, Plöger, Wilson, e. a.) wat reken dat die gebed goed binne die res van die hoofstuk en boek inpas. ${ }^{3}$

2 Verskillende redes word angebied: (1) Die gebed pas nie in binne die Hebreeuse skryfstyl van die res van die boek Daniël nie (Hartman \& Di Lella 1978:246); (2) Die gebed verskaf nie voldoende antwoord vir die behoefte aan 'n goddelike openbaring wat die gebed voorafgaan nie (Wilson 1990:91); (3) Geleerdes wys op die naam van Jahwe wat in vers 4 asook in verse 8, 10, 13 en 14 voorkom. Die Goddelike naam Jahwe (ook genoem Tetragrammaton) word nie in die res van die boek Daniël gebruik nie (Anderson 1984:106); (4) Die gebed vertoon 'n Deuteronomistiese siening van die geskiedenis wat drasties verskil van die deterministiese siening wat in die res van die boek voorkom (Collins 1984:91); (5) Charles (1929:226) beweer dat die slot van die hoofstuk 9 nie die inhoud van die gebed (smeking om vergifnis en bevryding) in aanmerking neem nie; (6) Hartman en Di Lella (1978:246) reken dat die inleiding (v. 4a) en slot (v. 20) duidelik na 'n latere invoeging verwys. Die inleiding is volgens hulle 'n woordelikse herhaling van vers 3 en die slot 'n ooglopende breuk in die sinsbou van die gebed.

3 Die volgende redes word as motivering vir die huidige plasing en eenheid van die gebed aangebied: (1) Jones (1968:489) reken dat die meeste van bogenoemde stellings (vgl. vorige voetnoot) waar is, maar dat dit nie bewys dat die gebed later as die res van die hoofstuk geskryf is nie; (2) Indien die gebed uit hoofstuk 9 verwyder word, sal die lengte van die hoofstuk nie met die ander hoofstukke in Daniël korreleer nie (Jones 1968:490); (3) Plöger (1965:135) meld dat die gebed 'n soortgelyke patroon as die ander hoofstukke in Daniël vertoon: 'n droom of 'n visioen en dan 'n interpretasie (óf die patroon van gevaar en redding). In hoofstuk 9 staan die gebed in die plek van die droom of visioen en dit vervul dieselfde funksie; (4) Wilson (1990:97-98) gee 'n verklaring vir die probleem van die plasing van die gebed binne sy huidige konteks. Die gebed 
Daar is nie 'n maklike oplossing vir die kwessie van die eenheid nie. Goldingay (1989:237) wys daarop dat baie van die argumente wat vir en teen die eenheid aangevoer word, bevraagteken kan word. Hy waag dit nie om 'n definitiewe uitspraak te doen nie. Volgens hom kan albei hipoteses waar wees. Daar was waarskynlik verskillende fases in die ontstaan van die boek met hoofstuk 9 wat moontlik deel van die laaste stadium uitmak (Gammie 1976:195, 196). ${ }^{4}$

Ten spyte van verskillende argumente moet daar tog erken word dat die gebed 'n onlosmaaklike deel van die boek Daniël is. Die gebed is waarskynlik doelbewus deur die outeur van Daniël ingevoeg en dit moet bestudeer word in verhouding tot die narratief waarin dit geplaas is (Balentine 1993: 104; Collins 1993:348). Skuldbelydenis en vergifnis is nie beperk tot een spesifieke historiese tydvak nie; daarom is 'n verskeidenheid van historiese kontekste versoenbaar met die literêre konteks. Van As (1961:104) argumenteer byvoorbeeld dat die ballingskap die volk se verdiende straf was en die belydenis van skuld en 'n bede om vergifnis goed hier inpas. Die rede vir die invoeging van die gebed in Daniël 9 is duidelik. Die einde van die lyding en nood kan slegs plaasvind as die volk boete doen en hulle skuld erken. Daniël onderneem om namens die volk die skuldbelydenis uit te spreek. Aan die ander kant reken Balentine (1984:107-108) weer dat hierdie gebed goed inpas binne die tydvak van Antiogus Epifanes IV (167-164 v C) toe die tempel ontheilig is, die volk verdruk is en gesmag het na vergifnis. ${ }^{5}$

Daar is geen probleme met die afbakening van die gebed nie. Die gebed word in vers 4 met drie terme ingelei: אמר en , ידה , Dit is belangrik dat verse 3 en 4a-c as integrale deel van die gebed beskou word, omdat dit die gesindheid van die bidder weergee, 'n gesindheid van berou en algehele toewyding. Die uiterlike gebedspraktyk word ook vermeld: vas, rouklere en die strooi van as oor die kop (Anderson 1984:106). Ná die gebed volg die goddelike antwoord by monde van Gabriël (vv. 22-27).

van Daniël is nie ' $n$ pleitroep om helderheid aangaande Jeremia se profesie van 70 jaar nie. Die gebed het ontstaan uit die "briewe" van Jeremia aan die gemeenskap in ballingskap wat in Jer. 29 opgeteken is. Die gebed is 'n poging van Daniël om die voorwaardes vir herstel wat in Jer. 29:12-14 gestel word, te vervul. Jahwe verwag dat die volk sy aangesig sal soek en hulle sondes sal bely terwyl die periode van 70 jaar sy einde nader; (5) Verskeie woorde van die gebed word in die antwoord van Gabriël (vv. 20-27) herhaal (Jones 1968:491492; Collins 1993:348).

4 Collins (1984:91) reken dat die gebed (vv. 3/4-19) later ingevoeg is deur die outeur van Dan. 9 en nié 'n ander redaktor nie.

$5 \mathrm{Vgl}$ bespreking by 2.6 oor die moontlike datering. 


\subsection{Vertaling en tekskritiek}

Die wortel סלח kom in twee verse (vv. 9 en 19) in die gebed van Daniël voor. Vers 9 kan as volg vertaal word:

By die Here ${ }^{6}$ ons God is barmhartigheid en vergifnis (סליחות), want

(כ) ons was opstandig teen Hom/U (ב)).

Die vertaling van die laaste gedeelte van vers 9 is belangrik vir die verstaan van vergifnis. 'n Hele aantal vertalings vertaal die partikel sief: "al was ons opstandig" (1983-AV); "alhoewel wij tegen U gezondigd hebben" (NV); "though we have rebelled against him" (NEB); "even though we have rebelled against him" (NIV) en andere. Volgens die 1933/53-AV, Aalders (1962:203), Lacocque (1979:174), Porteous (1979:131), Goldingay (1989:225) en Collins (1993:344) moet dit eerder as 'n redegewende sin vertaal word. In die lig van die gebruik van die partikel ${ }^{7}$ word dit as 'n redegewende sin verstaan en gevolglik met "want" vertaal.

Goldingay (1989:227) reken dat die woord כ nie goed in hierdie sin inpas nie en dat dit eerder die begin van 'n nuwe sin moet wees: "Because we have rebelled against him (10) and have not listened to the voice...." Goldingay se voorstel is 'n moontlikheid. Die skrywer se eie vertaling beskou egter vers $9 \mathrm{~b}$ as deel van 9a en nie deel van 10 nie.

Die laaste woord in vers 9 lees (teen Hom). In vers 10 word daar ook in die derde persoon oor God gepraat. Die feit dat in hierdie twee verse na God in die derde persoon verwys word, skep die indruk dat die bidder hom meer tot sy volk as tot God rig soos in sommige Psalms die geval is (Van As 1961:105). Daar is voorbeelde van gebede in die Joodse gemeenskap waar in dieselfde gebed tot God gebid word en dan weer oor God gepraat word. Dit is deel van die openbare gebed dat die gemeenskap gelei word om te bid, maar ook geleer word hoe om te bid in die verloop van die smekinge (Towner 1984:133). Op grond van bogenoemde gegewens moet dit as derde persoon vertaal word, maar op grond van literêre getuienis in die res van die gebed moet dit eerder as tweede persoon ("teen U") vertaal word. Waarskynlik is albei vertalingsmoontlikhede binne die literêre konteks gepas.

6 Daar is ' $n$ paar vertalingsmoontlikhede in hierdie vers. Aan die begin van die sin staan die woord לאדגי. As 'n mens die voorsetsel ל direk vertaal, moet dit as "by die Here" gelees word. In die konteks van vv. 8 en 9 kan dit ook met "maar" vertaal word. Daar word vir die eerste vertalingsmoontlikheid gekies.

7 Vgl. Aejmelaeus (1986:207) en Van der Merwe (1993:38-41). 
'n Moontlike vertaling vir vers 19 is:

Here, ${ }^{8}$ hoor! Here, vergewe! Here, merk op/gee aandag en doen dit! Moenie uitstel nie, ter wille van Uself/om U ontwil, my God; want $\mathrm{u}$ Naam is oor u stad en u volk uitgeroep.

\subsection{Opbou en struktuur}

Die gebed kan as volg verdeel word: ${ }^{9}$

(1) Gebedshouding en uiterlike gebedspraktyk 3

(2) Inleiding tot gebed 4a-c

(3) Aanroeping 4d-f

(4) Skuldbelydenis $5-11 \mathrm{~b}$

(4.1) Direkte skuldbelydenis 5-6

(4.2) Belydenis gekombineer met erkenning van

God se regverdigheid 7-8

(4.3) Vergifnis van God ten spyte van opstandigheid 9

(4.4) Belydenis in terme van verbreking van verbond 10-11a

(5) Beskrywing van Goddelike oordeel $11 \mathrm{c}-14^{10}$

(5.1) Bevestiging dat die verbondsvloeke vervul sal word 11c-13

(5.2) Bevestiging van God se regverdigheid 14

(6) Smekinge om genade en vergifnis 15-19

(6.1) Eerste smeking om genade 15-16

(6.2) Tweede smeking om genade en vergifnis 17-19

Towner (1971:210) meld dat die prosa-boetegebede 'n spesifieke struktuur het: toesegging ("ascription"), skuldbelydenis en smeking. In Daniël 9 is al drie hierdie elemente teenwoordig: vers 4 (toeskrywing); vers 5-14 (skuldbelydenis); en vers 15-19 (smeking).

In die aanroeping van God (vv. 4d-f) word meer gedoen as bloot om God se aandag te trek. Die basiese woordeskat en ideologiese raamwerk van die verbondsteologie word bekendgestel. Die outeur se taal weerspieël Ne-

8 Sommige manuskripte het אדני in plaas van מהוה in belangrikste teksgetuienis lees egter אדני.

9 Hierdie voorstel neem die voorstelle van die volgende geleerdes in ag: Van As (1961:104); Baldwin (1978:165-167); Collins (1984:89); Goldingay (1989: 235); Balentine (1993:105); en Potgieter (1993:2-4).

10 Die oorgang tussen vv. 11b en c word gekenmerk deur die gebruik van die passiewe werkwoord in v. 11c (Collins 1984:89). 
hemia se aanroeping in Nehemia 1:5 en hierdie formule is waarskynlik 'n samevoeging van Deuteronomium 7:9 en 21 (vgl. ook Neh. 9:32 en 1 Kon. 8:23) (Werline 1998:69).

Die skuldbelydenis (vv. 5-11a) word ingelei met die opeenstapeling van vyf werkwoorde wat Israel se toestand beskryf: עטא (sondig); עוה (verkeerd of ongeregtigheid doen); רשע (goddeloos handel, kwaad doen); מרד (in opstand gekom); סור (afwyk van [u gebooie]). ${ }^{11}$ Hierdie uitdrukkinge word opgesom met twee algemene skuldbelydenisse wat regdeur hierdie gedeelte voorkom: "ons het gesondig" (vv. 5, 8, 11) en "ons het nie geluister nie" (vv. $6,10,14)$. In verse 5-11a word die deugde van God met die mislukking van Israel gekontrasteer. Die kontras word versterk met die aanspreekvorm אדני (Here) in verse 7, 8 en 9 (Baldwin 1978:165; Balentine 1993:105). Die kern van die skuldbelydenis in vers 5-11a word opgesom met die woorde van vers 7 (Porteous 1979:137): "U is regverdig, Here. Dit is onsself wat hierdie ellende oor ons gebring het".

Die skuldbelydenis word gevolg deur'n beskrywing van die oordeel (vv. 11b-14). Hierdie beskrywing word ingelei deur die verandering van die aktiewe na die passiewe vorm van die werkwoord: "Daarom het U die vloek wat met 'n eed bevestig is en wat opgeteken is....." (Collins 1984:89).

In vers 15-19 is daar twee smekings (15-16; 17-19) wat met die woord ועתה (en nou) ${ }^{12}$ ingelei word. Die Naam van die Here word sewe keer in hierdie vier verse aangeroep. Die tweede smeking in vers 17-19 word gekenmerk deur die gebruik van die imperatief שמע (hoor) wat in elkeen van die verse voorkom. In vers 19 word die שמע gevolg deur die woord קשב (opmerk, gee ag) wat dui op 'n groter dringendheid (Aalders 1962:209; Balentine 1993:106). Elkeen van die smekings word deur 'n rede gemotiveer (Collins 1984:89).

Clements (1985:199) meld dat daar'n treffende spirale beweging in die gebed voorkom. Eerstens word gewys op Israel se sonde as 'n oortreding van die wette van Moses en dan die smeking om vergifnis (v. 9). Die siklus van belydenis en smeking word met groter intensiteit herhaal en eindig met 'n sterker pleitroep om vergifnis. Die klimaks word bereik met die woorde van vers 19. Clements wys op 'n interessante tendens; tog kan 'n mens nie heeltemal praat van siklus van belydenis en smeking om vergifnis nie. Die gebed eindig met 'n smeking of pleitroep om vergifnis, maar vers 9 is nie

11 Vgl. 1 Kon. 8:47 en Ps. 106:6.

12 Die woord ועתה wys dikwels op die oorgang van 'n skuldbelydenis na 'n smeking om genade (vgl. Eks. 32:31-32; 1 Sam. 12:10; 15:24; e. a.) (Collins 1993:350). 
'n direkte smeking om vergifnis nie. Dit is slegs 'n verwysing na God wat vergewe. Vers 19 kan egter as die hoogtepunt van die gebed beskou word (Van As 1961:106; Towner 1984:139).

\subsection{Gattung}

Potgieter (1993:1-6) tipeer die gebed van Daniël as 'n אנא/אנה-gebed (vgl. ook Gen. 50:17; Eks. 32:31-32; Jes. 38:2-3; 2 Kon. 2:2-3; Jona 1:14; 4:2; Neh. 1:5-11). Volgens hom deel bogenoemde gebede die volgende struktuurelemente: (1) Almal is ingebed in prosa; (2) Daar kom 'n inleiding voor; (3) Die אנא/אנה-formule word aangetref; (4) 'n Versoek met imperatiewe saam met die woordjie (tog); (5) Woorde vir sonde kom in die gebede voor; (6) Die versoek word gevolg deur ועתה. Potgieter se tipering wys op sekere belangrike struktuurelemente, maar dit kan nie as enigste grond vir die vasstelling van 'n Gattung dien nie. Die gebed moet ook met ander literêre vorme vergelyk word.

Die gebed van Daniël toon heelwat ooreenkomste met die klaaglied van die volk. In hierdie gebed is die oorsake van die nood duidelik: die ongehoorsaamheid van die volk teen die gebooie en bepalinge van Jahwe (v. 5) of die wet van Moses (vv. 11 en 13).

In die klassieke vorm van die klaaglied van die volk word daar na die duur van die nood gevra (hoe lank nog?), maar in die gebed van Daniël is daar nie sprake van so 'n vraag nie. Teen die einde van die gebed $(15 b)$ is daar 'n hernude skuldbelydenis en 'n uitvoerige smeking om hulp (vv. 1619), maar steeds geen vraag na die duur van die lyding nie (Plöger 1965: 137; Reventlow 1986:283; Goldingay 1989:235).

Daniël 9:4-19 moet waarskynlik as 'n "prosa-boetegebed" getipeer word. Hierdie aanname word gemaak omdat dit verskeie ooreenkomste met drie ander lang prosagebede (Esra 9:6-15; Neh. 1:5-11; 9:6-37) ${ }^{13}$ vertoon (Hornig 1958:645). Bogenoemde boetegebede vertoon die volgende gemeenskaplike eienskappe:

- Hulle word geïdentifiseer deur die gebruik van die Hitpa'el-vorm van die stam ידה (om sonde te bely). ${ }^{14}$ Die spesifieke gebruik van die stam ירה kom slegs tien keer in die Masoretiese teks voor. Ses van die tien verwysings word in die vier boetegebede aangetref.

13 Werline (1998:65-108) meld dat Dan. 9 ook talle ooreenkomste met Barug 1: 15-3:8 vertoon.

14 Vgl Esra 10:1; Neh. 1:6; 9:3; en Dan. 9:4 en 20. Die wortel ידה word ook in die konteks van die lof gebruik (vgl. Mayer 1986:441-443). 
- Hierdie gebede is meer uitgebreid as die ander prosagebede. Sekere gedeeltes word ontleen aan vroeëre gebede en gekombineer in 'n struktuur wat beweeg van toesegging ("ascription") na skuldbelydenis en laastens na smeking.

- Al vier gebede bevat 'n boetekarakter en kan verbind word met die manier van boetedoening wat in die gebed van Salomo gepropageer word (1 Kon. 8:46-47, 49).

- Die narratiewe waarin die gebede gegiet is, gee nie 'n versekering van Jahwe se vergifnis of enige ander direkte antwoord nie. Dit is slegs Daniël 9 wat na 'n verdere gesprek tussen God (d.m.v. die engel Gabriël) en die mens verwys (Towner 1971:209-211).

\subsection{Sitz im Leben}

Daniël 9:3/4-19 is waarskynlik 'n gedeelte wat uit die liturgiese tradisie oorgeneem is omdat dit herinner aan die gebede wat in die kultus vir boetedoening gebruik is (vgl. 1 Kon. 8:22-53, Esra 9:6-15 en Neh. 9:6-37) (Lacocque 1979:180; Reventlow 1986:282).

Die Ou-Testamentiese gebede van dank en skuldbelydenis is al hoe meer as dade van vroomheid gesien wat selfs die konkrete dade (vgl. offer) in die kultus vervang het (Towner 1971:212). Die woordelikse inhoud van die gebed van Daniël vertoon geen ooreenkoms met "konkrete" kultiese praktyke nie, maar wel die nabye literêre konteks. In vers 3 word melding gemaak van 'n vas- en rou-seremonie en in vers 21 van die aandoffer. Die moontlikheid bestaan dat Daniël 9 deel was van die liturgie van die versoeningsdae, veral die Groot Versoendag (Lacocque 1976:141-142).

Die bestudering van die Tora en die liturgiese styl van gebed in Daniël 9 veronderstel die agtergrond van 'n sinagoge. In die sinagoge is die bestudering van die Tora aangemoedig asook 'n manier van bid wat die bestudering van die Tora reflekteer (Goldingay 1989:238). Reventlow (1986:284285) wys daarop dat selfs Daniël 'n "skrifgeleerde" is wat na die betekenis van die sewentig jaar van verwoesting soek. So word die gebedsoorlewering geaktualiseer en "verskriftelik" wanneer die gebed in Daniël 9 vervul word. Daniël 9 is in prosavorm en nie soos sommige ander gebede in poëtiese vorm geskryf nie. Bogenoemde gegewens dui op moontlike veranderinge in die gebedspraktyke van die tweede tempel en sinagoge teenoor die vooreksiliese gebruike. 


\subsection{Samestelling, redaksie en datering}

Lacocque (1976:141; 1979:179) reken dat die oorsprong van die gebed tussen 587 en 538 v.C. moet wees, terwyl die gedeeltes wat die gebed omraam (verse 1-3 en 21-27) waarskynlik tussen 166 en 164 v.C. gedateer kan word. Hy dateer dit in hierdie tyd omdat die volgende sake ter sprake kom: die verbond en Tora speel 'n baie belangrike rol (vv. 4, 5 en 10); Daniël is soos al die ander profete die "dienaar van die Here" (vv. 6, 10 en 11); die sosiale strukture bestaan uit konings, goewerneurs, prinse, vaders en "mense van die land" (vv. 6 en 12); en daar is 'n duidelike afwesigheid van priesters.

Sommige uitdrukkinge in die gebed wys op die Deuteronomistiese traחisie: חסד (verbondstrou), אורה (wet), שהב (liefde), שוב (bekeer) en היום (vandag), asook die betekenis van Moses, konings en profete as predikers van Jahwe se leringe (Goldingay 1989:234; Van Deventer 2000:62-75). In vers 19 vorm die Deuteronomistiese "Naam-teologie" deel van die motivering vir vergifnis (Towner 1984:139). Die gebed kan egter nie slegs as 'n Deuteronomistiese gebed getipeer word nie.

Daniël 9 toon verder ooreenkomste met die gebed in Nehemia 9. Reventlow (1986:284) reken dat Daniël 9 se ontstaanstyd nie te ver van dié van Esra-Nehemia is nie. Esra en Nehemia het opgetree in 539-428 v.C., maar die boeke van Esra en Nehemia is waarskynlik tussen 380 en 350 v.C. opgeteken. Aan die ander kant is daar diegene wat reken dat die finale optekening van Daniël 9 nie voor die derde eeu voor Christus is nie.

Die probleem rondom die ontstaanstyd kan opgelos word deur na die ontstaanstyd van die hele boek te kyk. Die meeste moderne geleerdes reken dat Daniël in die tyd van Antiogus IV Epifanus (175-164 v.C.) geskryf is (vgl. Spangenberg 1985:275; Burden 1987:212; Nel \& Human 2000:293298). Daar kan gekonkludeer word dat Daniël 9 waarskynlik finaal tussen 168 en 165 v.C..$^{15}$ geredigeer is. Dit is egter moontlik dat 'n gedeelte van die gebed vroeër ontstaan het, sommige gedeeltes so vroeg as 586 v.C. Waarskynlik is hierdie vroeë gedeeltes verder geredigeer omdat die gebed ook 'n eksiliese (vgl. vv. 7 en 16) en na-eksiliese ${ }^{16}$ konteks veronderstel (Goldingay 1989:238). Die skrywer/redaktor het waarskynlik aangesluit by 'n

15 Collins (1984:92) stel voor dat Dan. 9 teen die einde van 167 of aan die begin van 166 v.C. opgeteken is.

16 Die gemeenskaplike boetegebed is volgens Goldingay (1989:235) 'n na-eksiliese verskynsel. Dit het ontwikkel vanuit die pre-eksiliese klag, maar daar is 'n verandering in die "waaromvraag" vanweë die invloed van die Deuteronomistiese teologie. 
ouer teologiese tradisie wat antwoorde moes verskaf in soortgelyke omstandighede, naamlik die verlies van die tempel en vreemde heerskappy (Van Deventer 2000:62-75).

Die debat rondom die moontlike ontstaanstyd het nie 'n wesenlike invloed op die verstaan van vergifnis nie. Daar is reeds vroeër in die artikel geargumenteer (vgl. 2.1) dat skuldbelydenis en vergifnis nie beperk is tot een historiese konteks nie. Vanaf die tyd van die Babiloniese Ryk tot met Antiogus IV Epifanes was daar by die volk 'n behoefte aan goddelike vergifnis.

\section{TEOLOGIESE DIMENSIE VAN VERGIFNIS}

Daniël se gebed om vergifnis staan nie alleen binne die Ou-Testamentiese tradisie nie. Daniël 9:4-19 se taalgebruik kom ooreen met 'n hele aantal Ou-Testamentiese gedeeltes. Die gebed is "gevorm" deur die gebed om vergifnis van Salomo (vgl. 1 Konings 8:46-53) en toon duidelike parallelle met drie ander boetegebede in Esra en Nehemia (Esra 9:6-15; Neh. 1:5-11; 9:6-37) (Towner 1984:139; O'Kennedy 2000:74, 84).

In Daniël 9:9 (vgl. ook Neh. 9:17 en Ps. 86) handel dit oor 'n herstel of verbetering van die bidder se situasie. Dit is opvallend dat daar in vers 9 geen direkte smeking om vergifnis is nie (wel in v. 19). Jahwe word slegs daaraan herinner dat $\mathrm{Hy}$ 'n goeie God is wat vergewe. Hierdie besondere gebruik van die verbale adjektief dui op 'n "göttliches Attribut" (Hausmann 1986:864).

Vers 9 sluit nou aan by vers 18 en 19. In vers 9 word vermeld dat Jahwe 'n God is wat barmhartig is en vergewe en in vers 18 word gepleit dat God juis liefde moet betoon, omdat Hy 'n barmhartige God is. Vers 19 is die hoogtepunt van die hele gebed. In hierdie vers is daar herinneringe aan 1 Konings 8:30, 34, 36 en Psalm 40:17. Daar is ook elemente van die vorige verse: "ter wille van Uself" (v. 17); "u Naam is oor u stad uitgeroep" (v. 18). Vers 19 beklemtoon die sterk liefdesverband tussen die bidder en God (Lacocque 1979:186).

In verse 18 en 19 word elke keer 'n motivering gegee hoekom God Hom moet ontferm en vergewe. Die eerste motivering verwys na God se barmhartigheid en die tweede na God se Heilige Naam. Velema (1972:65) meld dat dit nie twee afsonderlike motiewe is nie. Volgens hom vorm God se Naam en sy barmhartigheid 'n eenheid deurdat God as Barmhartige getipeer kan word. In Daniël 9 word nie slegs na God se barmhartigheid verwys nie. In die res van die gebed word Jahwe agtereenvolgens herinner aan Sy verbondstrou teenoor almal wat sy gebooie onderhou, die redding uit Egipte, sy teenwoordig in sy tempel en stad, sy heilsopenbaring en die ver- 
bondenheid van sy Naam aan stad en volk. In hierdie hele gebed om vergifnis staan Jahwe self in die middelpunt. Die gebed is in die eerste plek 'n verkondiging van Jahwe se wese en 'n verheerliking van sy mag (Van As 1961:106; Balentine 1993:108).

Die gebed van Daniël en Gabriël se antwoord verseker nie die onvoorwaardelike skenking van Goddelike vergifnis nie. Die struktuur en inhoud van Daniël 9:3/4-19 veronderstel dat vergifnis aangebied sal word as God herhaaldelik as 'n regverdige, liefdevolle en vergewende God bely word. In die gebed is daar 'n bepaalde verband tussen die volk se berou, skuldbelydenis en smeking, en die Goddelike vergifnis (Collins 1984:95; Balentine 1993:108).

Alhoewel die skuldbelydenis beklemtoon word, verkondig die gebed nie die "selfverlossing" van die mens nie. Die verlossing lê uitsluitlik by die barmhartige en vergewensgesinde God. Die gebed beklemtoon nie dat God "verplig" moet word om 'n regverdige volk te red nie. Inteendeel, dit is juis 'n bede om vergifnis weens die opstandigheid van die volk (v. 9) (Plöger 1965:138; Porteous 1979:139; Helberg 1994:100-102).

In die skuldbelydenis pak Daniël nie die skuld op 'n ander volk of God nie. Volgens vers 8 is almal skuldig: konings, leiers, familiehoofde, almal. Almal het God se vergifnis nodig. Hierdie is een van die mees omvattende skuldbelydenisse wat in die Ou Testament voorkom. Slegs in Nehemia 9:32 en 34 kom 'n soortgelyke skuldbelydenis voor met die invoeging van die priesters (Van As 1961:105; Collins 1993:350). In Nehemia 9:33-34 word daar verwys na almal wat "goddeloos gehandel het" (רשע) terwyl in Daniël 9 daar verwys word na almal wat "gesondig het" (Tט).

Die gebed van Daniël smeek dat God sal vergewe en dat Hy dit so spoedig moontlik moet doen ("moenie uitstel nie": vs. 19) (Aalders 1962: 209). Dit is interessant dat die bidder die woorde "moenie uitstel nie" aan “ter wille van Uself” koppel. 'n Mens sou reken dat die spoedige vergifnis eerstens ter wille van die volk moet geskied en nie eerstens ter wille van God nie. Moontlik was die bidder 'n bietjie skynheilig in sy smeking om vergifnis.

Die vergifnis in Daniël 9 is vir die "internasionale" Israel en nie beperk tot 'n spesifieke geografiese gebied nie. Vers 7 verskaf'n omvattende definisie van die volk Israel. Dit bevat die gemeenskappe wat in Juda woon sowel as die Diaspora-Jode in die verskillende lande (Clements 1985:200): 
....oor die mense van Juda, oor die inwoners van Jerusalem, oor die hele Israel, dié wat naby is sowel as dié wat ver is, ver in al die lande waarheen $U$ hulle verstrooi het oor hulle ontrou teenoor $U$.

Hierdie omvattende definisie maak dit moontlik dat die gebed betekenis het vir feitlik enige historiese tydvak.

Laastens kan opgemerk word dat die gebed nie goddelike vergifnis verseker nie; die teks van die gebed asook die antwoord van Gabriël (vv. 2027) maak nie hiervan melding nie. Aan die ander kant "oorreed" die gebed 'n mens om te glo dat God 'n regverdige, liefdevolle en vergewensgesinde God is wat vergifnis sal skenk as jy jou sondes voor Hom bely.

\section{SLOT}

Daniël 9:4-19 kan getipeer word as 'n prosa boetegebed en vertoon ooreenkomste met ander boetegebede in die Ou Testament (1 Kon. 8; Esra 9; Neh. 1 en 9). Vergifnis is 'n sentrale element in die gebed van Daniël. Die wortel ok twee keer in die gebed voor en verskeie ander terme en frases verwys na God se liefde, regverdigheid, barmhartigheid en genade. Daniël 9:4-19 eindig met 'n hoogtepunt as daar in vers 19 om vergifnis gesmeek word. Die presiese ontstaanstyd van hierdie gebed is onseker, maar 'n skuldbelydenis en gebed om vergifnis sou binnne verskillende historiese omstandighede kon inpas.

In hierdie gebed word die volgende belangrike elemente ten opsigte van vergifnis beklemtoon:

- Die motivering vir die vergifnis lê nie in die volk se gehoorsaamheid nie, maar word gegrond in God se genade en barmhartigheid. Die volk se opstandigheid word juis beklemtoon as 'n rede hoekom hulle vergifnis nodig het.

- Die struktuur en inhoud van die gebed veronderstel dat skuldbelydenis ' $n$ belangrike element is in die proses van vergifnis. Die skuld word nie net op sekere persone of konings geplaas nie; almal is skuldig.

- Vergifnis is vir die “internasionale” Israel en nie beperk tot 'n spesifieke geografiese gebied nie. 


\section{BIBLIOGRAFIE}

\section{AALDERS G C}

1962. Daniël. Kampen: J H Kok. (COT.)

Aejmelaeus A

1986. Function and interpretation of כ in Biblical Hebrew. JBL 105:93-209.

\section{ANDERSON R A}

1984. Signs and wonders: a commentary on the book of Daniel. Grand Rapids: Eerdmans.

BALDWIN J G

1978. Daniel. Leicester: Inter-Varsity Press. (TOTC.)

BALENTINE S E

1993. Prayer in the Hebrew Bible: the drama of divine-human dialogue. Minneapolis: Fortress Press.

BURDEN J J

1987. Die boek Daniël. In: Burden J. J. \& Prinsloo W. S. (reds.), Tweegesprek met God: predikers, digters en wysgere, 195-220. Kaapstad: Tafelberg Uitgewers. (Literatuur van die Ou Testament 3.)

\section{Charles R H}

1929. A critical and exegetical commentary on the book of Daniel. Oxford: Clarenden Press.

Clements R E

1985. In spirit and trutb: insights from Biblical prayers. Atlanta: John Knox Press.

COLlins J J

1984. Daniel. Grand Rapids: Eerdmans. (FOTL.)

1993. Daniel. Minneapolis: Fortress Press (Hermeneia.)

CONRADIE A J

1978. Gebed en gebedsverhoring in die Bybel. D.D.-proefskrif, Universiteit van Pretoria.

\section{GAMMIE J G}

1976. The classification, stages of growth, and charging of intentions in the book of Daniel. JBL 95:191-204.

\section{GOLDINGAY J E}

1989. Daniel. Dallas, Texas: Word Books. (WBC.)

Hartman L F \& Di Lella A A

1978. The book of Daniel. New York: Doubleday \& Company. (AB.)

HAUSMANN J

1986. s. v. סלח. TWAT 5:859-868. 
O'Kennedy

Vergifnis in die gebed van Daniël (Dan. 9:4-19)

HeLberg J L

1994. Die boek Daniël. Kaapstad: NG Kerk uitgewers. (SBG.)

HORNIG B

1958. Das Prosagebed der nachexilischen Literatur. TLZ 9:644-646.

JONES B W

1968. The prayer in Daniel IX. VT 18:488-493.

La CocQue A

1976. The liturgical prayer in Dan 9. HUCA 47:119-142.

1979. The book of Daniel. London: SPCK.

LOUW P U

1979. Gebed in die Ou Testament: 'n studie van die grondbetekenis en liggaamsbelewing in die gebed. M. Th.-tesis, Universiteit van Stellenbosch.

MAYer G

1986. s. v. ידה. TDOT 5:431-443.

Nel M \& Human D J

2000. Die Daniëlboek: enkele inleidingsprobleme vanuit 'n laat datering. OTE 13/3:293-308.

O'KENNEDY D F

2000. The prayer of Solomon (1 Ki 8:22-53): paradigm for the understanding of forgiveness in the Old Testament. OTE 13/1:72-88.

O'KenNedy D F \& Olivier J P J

1996. Die konsep vergifnis in die Ou Testament. NGTT 37/4:496-508.

\section{PORTEUS N}

1979. Daniel. Second revised edition. London: SCM Press.

\section{PlÖGER O}

1965. Reden und Gebeten im deuteronomistischen und chronistischen Geschichtswerk. In: Schneemelcher W. (Hrsg.), Festschrift für Günther Dehn, 3549. Neukirchen: Neukirchener Verlag.

\section{PotgIETER J H}

1993. Die אגה/אנא gebede van die Ou Testament. Referaat gelewer op 15 September 1993 te SAVSEM-kongres, Stellenbosch.

\section{REVENTLOW H G}

1986. Gebet im Alten Testament. Stuttgart: Verlag W Kohlhammer.

\section{SPANGENBERG I J J}

1985. Daniël 9: 'n voorspelling van die kruisigingsdatum van Jesus Christus? NGTT 26:271-281. 


\section{TOWNER W S}

1971. Retribution theology in the apocalyptic setting. USQOR 26:203-214.

1984. Daniel. Atlanta: John Knox Press. (Interpretation.)

\section{VAN As J J}

1961. Skuldbelydenis en genadeverkondiging in die Ou Testament. Utrecht: Elinkwijk.

\section{VAN DER MERWE C H J}

1993. Old Hebrew particles and the interpretation of the Old Testament texts. JSOT 60:27-44.

\section{VAN DeVenter H J M}

2000. The end of the end, or, what is the Deuteronomist (still) doing in Daniel? In: De Moor J. C., Van Rooy H. F. \& Vervenne M. (eds.), Past, present, future: the Deuteronomistic history and the prophets, 62-75. Leiden: Brill. (OTS 44.)

VELEMA W H

1972. Gebeden in de Bijbel. Kampen: J H Kok.

\section{VENTER P M}

1997. Intertekstualiteit, kontekstualiteit en Daniël 9. In die Skriflig 31/4:327-346.

\section{WERLINE R A}

1998. Penitential prayer in second temple Judaism: the development of a religious institution. Atlanta, Georgia: Scholars Press.

\section{WILSON G H}

1990. The prayer of Daniel 9. Reflection on Jeremia 29. JSOT 48:91-99.

$\begin{array}{ll}\text { Trefwoorde } & \text { Keywords } \\ \text { Ou Testament } & \text { Old Testament } \\ \text { Gebed } & \text { Prayer } \\ \text { Vergifnis } & \text { Forgiveness } \\ \text { Daniël 9:4-19 } & \text { Daniel 9:4-19 }\end{array}$

